\title{
Immunologic Storm Simulating Systemic Lupus Erythematosus Following Parvovirus B19 Infection
}

\author{
Roxana González-Mazarío ${ }^{a}$, Luisa Suárez Álvarez ${ }^{\mathrm{b}}$, Luisa Micó Giner ${ }^{\mathrm{a}}$, Inés Moret Tatay ${ }^{\mathrm{c}, \mathrm{d}}$, Miguel Salavert Lleti ${ }^{\mathrm{e}}$
}

\author{
${ }^{a}$ Department of Internal Medicine, Hospital Universitari i Politècnic La Fe, Valencia, Spain \\ ${ }^{b}$ Department of Emergency Hospital Dr. Peset, Valencia, Spain \\ 'Instituto de Investigación Sanitaria, Hospital La Fe, Valencia, Spain \\ ${ }^{\mathrm{d}}$ CIBERehd, Barcelona, Spain \\ Infectious Disease Unit, Hospital Universitari i Politècnic La Fe, Valencia, Spain
}

\begin{abstract}
Background: The appearance of symptoms compatible with systemic autoimmune diseases has been described in relation to several viral infections like HIV, cytomegalovirus and especially PVB19, depending on the evolution of the immunological condition of the host and their age. We present a young immunocompetent male patient, with clinical manifestations simulating systemic lupus erythematosus (SLE) with important activation of cytokines.
\end{abstract}

Methods: For quantification of the different cytokines in plasma, a commercially available multiplex bead immunoassay, based on the Luminex platform (Cat \# HSCYTO-60SK-08, Milliplex ${ }^{\circledR}$ MAP High Sensitivity, Millipore), was used according to the manufacturer's instructions. All samples were run in duplicate and the data (mean fluorescence intensity) were analyzed using a Luminex reader. The mean concentration was calculated using a standard curve.

Results: The clinical evolution was favourable without the need for any specific treatment, showing complete recovery after two months. Whilst the symptoms and viral charge were disappearing, the anti-DNA continued to increase and we demonstrate important activation of IL-10, IL-6 and TNF $\alpha$ cytokines as a result of a hyperstimulating response by an immunocompetent hyperfunctional system, which persists after clinical improvement. We should emphasize the behaviour of two cytokines: IL-12p70 and IL-2, which showed opposite tendencies.

Conclusions: Viral infections, especially PVB19, can produce or simulate several autoimmune diseases as a hyperstimulation response from an immunocompetent hyperfunctional system. Consequently, a persistent increase of autoantobodies and important activation of cytokines, even after clinical improvement and seroconversion, can be demonstrated.

Keywords: Parvovirus B19 infection, SLE, cytokines

Received: 01/10/2014

Accepted: $20 / 11 / 2014$

Published: 06/02/2015

How to cite this article: González-Mazarío R, Suárez Álvarez L, Micó Giner L, Moret Tatay I, Salavert Lletí M. Immunologic Storm Simulating Systemic Lupus Erythematosus Following Parvovirus B19 Infection. EJCRIM 2015;2:doi: 10.12890/2015_000154

Conflicts of Interests: The authors declare that they have no conflicts of interest related to this research.

This article is licensed under a Commons Attribution Non-Commercial 4.0 License 


\section{Introduction}

Parvovirus B19 (PVB19), a member of the Parvoviridae family (gen. Erythrovirus), was accidentally discovered in 1975 by Cossart et al. and the first clinical communication of infection appeared in 1981 [1-3].

In young adults, the prevalence of PVB19 infection is estimated to be between $30 \%$ and $60 \%$, and in the elderly population it may even reach 90\%. It is more common in women than in men. PVB19 is highly contagious. Even though infections appear throughout the year, they are more frequent in spring and summer.

Transmission of the infection can take place through the respiratory tract, blood transfusions and haemoderivatives, as well as vertical transmission from mother to foetus. Fomite transmission cannot be ruled out because of the virus's high resistance to inactivation. Viraemia takes place between 7 and 10 days after exposure, and the patient can be contagious before symptoms appear and until they do [4, 5].

Clinical manifestations may vary from one patient to another, mainly depending on the immunological condition of the host and their age. This makes it difficult to diagnose in immunocompetent adults since it may develop in an atypical way or even be asymptomatic.

In $50 \%$ of cases, it appears to be simply a common cold (body malaise, fever and muscular pain) and only $25 \%$ of cases include the classic symptoms of exanthema, mild cytopenia (especially anaemia), arthralgia and/or arthritis.

Arthropathy (symmetric acute polyarthritis) is the most common manifestation in adults ( $80 \%)$. Rash is less frequent and characteristic, whereas in children it is usually the cause of infectious erythema, known as "fifth disease".

Bicytopenia is very infrequent in immunocompetent patients. Nevertheless, in immunocompromised patients, PBV19 can produce leukopenia and transitory aplastic anaemia with reduced reticulocytes.

In patients with haemolytic diseases, it may cause transitory aplastic crises, although infection in immunosuppressed patients may be expressed as chronic anaemia. In patients with malaria, it contributes to the pathogenesis of severe anaemia $[4,6]$.

In pregnant women, although infrequently, it may lead to severe foetal anaemia and heart failure, which can develop into "hydrops fetalis", and in some cases even foetal death[10].

Diagnosis is based on identification of specific antibodies. The gold standard molecular technique is DNA detection through PCR (real-time quantitative PCR), as this allows viral DNA identification for months or even years after the acute infection episode.

Specific immunoglobulin M (IgM) antibodies can be detected as of Day 10 or 12 and may persist for 2-6 months. Immunoglobulin G (IgG) antibodies appear 15 days after infection and can persist for the life of the patient. This antibody overlap explains the common finding of positive antibodies to both IgG and IgM during the first weeks or even months of infection $[2,4]$.

In most cases, symptoms disappear within a few weeks, but in other cases they persist for months or even years [8] and can evolve into chronic disease.

Acute viral disease can induce transient autoimmune responses in both adults and in children, with mildly elevated antibodies (at low titres). Progression to autoimmune diseases is uncommon although possible due to T-cell proliferation and cytokine production with autoimmune cell recruitment, resulting in organ damage and chronic autoimmune diseases.

In summary, the appearance of symptoms compatible with systemic autoimmune diseases, even with 
immunodeficiencies or immunomodulation phenomena, has been described in relation to several virus infections (HIV, cytomegalovirus) and especially with PVB19, which may be involved in up to $3 \%-4 \%$ of reactive arthritis and be associated with, or even simulate, the symptoms of various diseases like rheumatoid arthritis, systemic lupus erythematosus (SLE), systemic sclerosis, idiopathic juvenile arthritis, Sjögren's syndrome, primary biliary cirrhosis, autoimmune cytopenia and vasculitis.

\section{Case report}

We present the case of a 33-year-old male engineer who attended the emergency room of our hospital in May 2012 because of low-grade fever; severe odynophagia; polyarthritis in wrists and interphalangeal joints of the right hand, which later also extended to the left hand; and arthralgia in elbows, knees, ankles, hips and cervical vertebrae, associated with a maculopapular rash on the trunk of 3-4 days' evolution.

The relevant aspects of his medical history were that 4 years earlier he had suffered an episode of haematuria during a viral infection followed by temporary episodes of microhaematuria in conjunction with mild infections, with kidney function always being normal. Although immunoglobulin A (IgA) nephropathy was suspected, the study was never completed.

He had also had an episode of paroxysmal supraventricular tachycardia 8 years earlier and was vaccinated against B hepatitis.

He was not taking any drugs and had no family history of autoimmune systemic diseases.

One interesting fact was that his daughter had suffered an upper respiratory tract infection with a rash 5 days before the onset of symptoms in our patient.

The physical examination only revealed inflammation and stiffness of the hand joints, pain on proximal palpitation of interphalangeal joints and inflammation of the fifth finger of the left hand, as well as pain when mobilizing large joints, with a very mild maculopapular rash on the trunk.

The only abnormal parameters in the blood test were C-reactive protein (CRP) (78 mg/dl) and creatine kinase (CK) (909 $\mathrm{U} / \mathrm{I})$. X-ray of the hands and chest was normal.

A non-steroidal anti-inflammatory treatment was initiated and the patient was referred to our Internal Medicine outpatient department. On the follow-up visit 1 week later, the joint signs and symptoms had clearly improved and the rash had disappeared.

Laboratory analysis showed persistent elevation of CRP (42.6 mg/dl), erythrocyte sedimentation rate (ESR) (44), lactate dehydrogenase (LDH) $667 \mathrm{U} / \mathrm{l}$ and fibrinogen $(520 \mathrm{mg} / \mathrm{dl})$. All other common parameters were normal.

Autoimmune study results were as follows: anti-nuclear antibodies (ANA) +1:640, with cytoplasmic pattern; anti-DNAdc (EliA) $204.0 \mathrm{UI} / \mathrm{ml}$; anti-smooth muscle (IFI) 1:80; and anti-cyclic citrullinated peptide (CCP) (enzyme-linked immunosorbent assay, ELISA) $22.3 \mathrm{U} / \mathrm{ml}$.

Anti-cardiolipin antibodies and lupus anticoagulant were positive. The rest of the antibodies (anti-RNP, anti-Sm, anti-Ro, anti-La and antineutrophil cytoplasmic antibodies) were negative.

Bone scintigraphy revealed polytopic joint disease in the inflammatory phase.

Even though the initial diagnostic suspicion was SLE, with 4 out of 11 classificatory criteria (ACR 1997)[11], several viral serology tests were requested, and all were positive to parvovirus B19 (IgG and IgM) with a viral load of 12,600 UI/ml. 
Under symptomatic treatment with diclofenac, the patient experienced clear improvement with reduction of the joint symptoms. The blood tests were normal after 2 months with parvovirus seroconversion (IgM negative and sustained IgG positive). While ANA titres decreased to negative, anti-nucleosome antibodies maintained low positive titres and anti-DNA dc antibodies continued increasing until reaching $354.0 \mathrm{UI} / \mathrm{ml}$.

At 16 months after the acute infection, the patient remained asymptomatic, without the appearance of any new SLE criteria. The final diagnosis was self-limited primary PVB19 infection.

The study was completed with an analysis of the cytokines most involved in the response to PVB19 according to the scientific literature. Their determination in blood was performed at three different times during clinical evolution: at the beginning, one month later and ten months later, once the virus seroconversion had been confirmed.

\section{Materials and methods of cytokine quantification}

Eight different cytokines, interleukin (IL)-1 $\beta,-2,-6,-10,-12$ and -13 , interferon (IFN) $\gamma$ and tumour necrosis factor (TNF) $\alpha$, were quantified in plasma. A commercially available multiplex bead immunoassay based on the Luminex platform (Cat \# HSCYTO-60SK-08, Milliplex ${ }^{\circledR}$ MAP High Sensitivity, Millipore) was used according to the manufacturer's instructions. All samples were run in duplicate. The data (mean fluorescence intensity) were analyzed using a Luminex reader and the mean concentration was calculated using a standard curve.

\section{Results}

The elevation of IL-10, IL-6 and TNF $\alpha$ cytokines, seen at the beginning of the symptoms, persisted after clinical improvement.

Differences over time were observed. While IL-10 reached maximum values during clinical evolution, TNF $\alpha$ and IL-6 showed an important increase at the beginning and then tended towards normal values in the last determination.
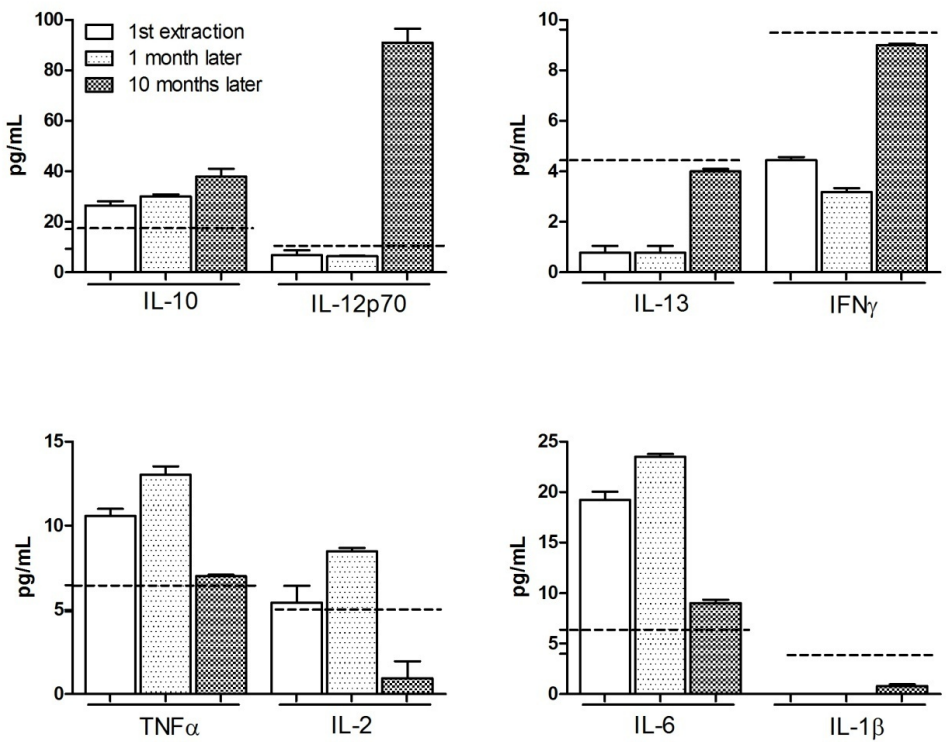

Figure 1: Cytokine pattern
On the other hand, IL-13 and IFN $\gamma$ showed an opposite tendency, reaching the maximum values at the time of clinical improvement and similar to the determinations made in healthy controls.

Cytokine IL-1 $\beta$ was virtually undetectable in all laboratory tests, with levels lower than expected. We should emphasize the behaviour of two cytokines: IL-12p70 and IL-2; the first being practically normal during the acute clinical period, with an important increase being observed during confirmation of seroconversion. On the other hand, IL-2 showed the opposite tendency, with a steep drop at the moment that IL-12p70 levels were highest. Figure 1 shows the results obtained. 
Cytokines with similar patterns have been classified into groups. Reference values in healthy subjects are marked as dotted lines.

\section{Discussion}

In the type of presentation described here, simulating a lupus flair, it is important to note the good evolution and clinical resolution without the need for any specific treatment such as intravenous corticosteroids, immunoglobulins and antiviral agents as a result of a hyperstimulation response by an immune-competent hyperfunctional system.

In these cases, the involvement of the heart, kidneys or other viscera or organs is more infrequent than that of the joints or skin; evolution with antibody titres tends to be low and of short duration.

Nevertheless, our case is remarkable for the high anti-DNA antibody titre and its persistence. Its clinical, biological, immunological and molecular evolution in the long term [12-28] still remains to be assessed. In addition, we observed the temporary overlapping of IgG and IgM antibodies already described by other authors.

Even though the role of the host immune system seems to be crucial in the anti-virus response,the presence of an inflammatory cell-mediated immune response, including TNF $\alpha$, IFN $\gamma$ and interleukin production, especially IL-2 and 6, as well as an immune response mediated by T-lymphocytes (CD 8+) $[29,30]$, has also been demonstrated in this clinical case.

The behaviour of the different cytokines would explain the patient's symptoms over time. On the other hand, it would support the existence of an idiosyncratic immunogenic ambience that favours immune events later on due to a possible effect of "immunologic reverberation" once the initial process has been triggered, even having decreased the initial symptomatology with an undetectable viral load.

Even though all these cytokines participated in the infectious process, its clinical correlation presents different aspects. While IL-6 is related with autoimmune processes and with arthralgia [31], IL-10 can indicate clinical manifestations similar to those typical of SLE $[32,33]$. IFN $\gamma$ determinations are of great importance, as its presence can indicate the persistence of PVB19 infection. The clinical significance of IL-13 has not yet been clarified.

IL-2 and IL12 have mirror behaviour. The drastic IL-2 decrease has been correlated with the risk of SLE after PVB19 infection [34], and IL12 is usually increased in SLE patients [31]. It is remarkable that in our case, although normal levels are maintained at the beginning, there is a drastic increase and maximum values are reached on the third determination.

In summary, the higher prevalence of acute or past PVB19 infection found in numerous autoimmune diseases could be due to either a genetic base or an idiosyncratic autoimmune environment that has not yet been clarified [12, 35-44].

Even though it has been suggested that the immune response, whether transitory or chronic, secondary to acute PVB19 infection could be involved in SLE pathogenesis, data favouring a superior prevalence of PVB19 infection in those patients compared to the general population are discordant. However, given the high proportion of bicytopenia in SLE, it could be under-diagnosed.

Cytokines participate in many important immunoregulation functions, playing an important role in immune system modulation. Abnormal/aberrant proinflammatory cytokines or Th1/Th2 response can influence infection control and lead to viral persistence. The identification of the immune response involved in this process and the characterization of biomarkers that could aid diagnosis are still to be clarified. 


\section{Learning Points}

- Virus infections, especially PVB19, can simulate autoimmune diseases.

- In both cases (virus infections and autoimmune diseases), autoantibody and cytokine activation can be present.

- Differential diagnosis is mandatory to avoid unnecessary treatments.

\section{References}

1. Cossart YE, Field AM, Cant B, Widdows D. Parvovirus-like particles in human sera, Lancet 1975;1:72.

2. Heegaard ED, Brown KE. Human parvovirus B19, Clin. Microbiol. Rev. 2002;15;485-505.

3. Servant A, Laperche S, Lallemand F, Marinho V, De Saint Maur G, Meritet JF et al. Genetic diversity within human erythroviruses: identification of three genotypes, J. Virol. 2002;76:9124.

4. Young NS, Brown KE. Parvovirus B19, N. Engl. J. Med. 2004;350:586.

5. Broliden K, Tolfvenstam T, Norbeck O. Clinical aspects of parvovirus B19 infection, J. Intern. Med. 2006;260:285304.

6. Sève P, Ferry T, Charhon A, Calvet A, Broussolle C. Systemic manifestations of parvovirus B19 infections, Rev. Med. Interne 2004;25:740-751.

7. Brown KE. The expanding range of parvoviruses which infect humans, Rev. Med. Virol. 2010;20:231-244.

8. Hayakawa H, Tara M, Niina K, Osame M. A clinical study of adult human parvovirus B19 infection, Intern. Med. 2002;41:295.

9. Woolf AD, Campion GV, Chishick A, Wise S, Cohen BJ, Klouda PT et al. Clinical manifestations of human parvovirus B19 in adults, Arch. Intern. Med. 1989;149:1153.

10.Dijkmans AC, de Jong EP, Dijkmans BA, Lopriore E, Vossen A, Walther FJ, Oepkes D. Parvovirus B19 in pregnancy: prenatal diagnosis and management of fetal complications, Curr. Opin. Obstet. Gynecol. 2012;24:95-101.

11. Hochberg MC. Updating the American College of Rheumatology revised criteria for the classification of systemic lupus erythematosus. Arthritis Rheum; 199;40:1725.

12.Adamson LA, Fowler LJ, Clare-Salzler MJ, Hobbs JA. Parvovirus B19 infection in Hashimoto's thyroiditis, papillary thyroid carcinoma, and anaplastic thyroid carcinoma, Thyroid 2011;21:411-417.

13. Mogensen TH, Jensen JM, Hamilton-Dutoit S, Larsen CS. Chronic hepatitis caused by persistent parvovirus B19 infection, BMC Infect. Dis. 2010;10:246.

14.Cope AP, Jones A, Brozovic M, Shafi MS, Maini RN. Possible induction of systemic lupus erythematosus by human parvovirus, Ann. Rheum. Dis. 1992;51:803-804.

15.Ramos-Casals M, Cuadrado MJ, Alba P, Sanna G, Brito-Zerón P, Bertolaccini L et al. Acute viral infections in patients with systemic lupus erythematosus: description of 23 cases and review of the literature, Medicine (Baltimore) 2008;87:311-318.

16. Negro A, Regolisti G, Perazzoli F, Coghi P, Tumiati B, Rossi E. Human parvovirus B19 infection mimicking systemic lupus erythematosus in an adult patient, Ann Ital Med Int 2001;16:125-127. 
17. Moore TL, Bandlamudi R, Alam SM, Nesher G. Parvovirus infection mimicking systemic lupus erythematosus in a pediatric population, Semin. Arthritis Rheum. 1999;28:314-318.

18.Tanaka A, Sugawara A, Sawai K, Kuwahara T. Human parvovirus B19 infection resembling systemic lupus erythematosus, Intern. Med. 1998;37:708-710.

19.Roblot P, Roblot F, Ramassamy A, Becq-Giraudon B. Lupus syndrome after parvovirus B19 infection, Rev. Rhum. Engl. Ed. 1997;64:849-851.

20.Díaz F, Collazos J, Mendoza F, De la Viuda JM, Cazallas J, Urkijo JC et al. Systemic lupus erythematosus associated with acute parvovirus B19 infection, Clin. Microbiol. Infect. 2002;8:115-117.

21.Severin MC, Levy $Y$, Shoenfeld $Y$. Systemic lupus erythematosus and parvovirus B-19: casual coincidence or causative culprit? Clin. Rev. Allergy Immunol. 2003;25:41-48.

22.Suzuki T, Saito S, Hirabayashi Y, Harigae H, Ishii T, Kodera T et al. Human parvovirus B19 infection during the inactive stage of systemic lupus erythematosus, Intern. Med. 2003;42:538-540.

23. Sève $P$, Ferry $T$, Koenig $M$, Cathebras $P$, Rousset $H$, Broussolle $C$. Lupus-like presentation of parvovirus B19 infection, Semin. Arthritis Rheum. 2005;34:642-648.

24.Bengtsson A, Widell A, Elmstâhl S, Sturfelt G. No serological indications that systemic lupus erythematosus is linked with exposure to human parvovirus B19, Ann. Rheum. Dis. 2000;59:64-66.

25. Aslanidis S, Pyrpasopoulou A, Kontotasios K, Doumas S, Zamboulis C. Parvovirus B19 infection and systemic lupus erythematosus: activation of an aberrant pathway? Eur. J. Intern. Med. 2008;19:314-318.

26. Nesher G, Osborn TG, Moore TL. Parvovirus infection mimicking systemic lupus erythematosus, Semin. Arthritis Rheum. 1995;24:297-303.

27.Rigante D, Mazzoni MB, Esposito S. The cryptic interplay between systemic lupus erythematosus and infections, Autoimmun. Rev. 2014;13:96-102.

28. Hession MT, Au SC, Gottlieb AB. Parvovirus B19-associated systemic lupus erythematosus: clinical mimicry or autoimmune induction? J. Rheumatol. 2010;37:2430-2432.

29. Norbeck O, Isa A, Pöhlmann C, Broliden K, Kasprowicz V, Bowness P et al. Sustained CD8+ T-cell responses induced after acute parvovirus B19 infection in humans, J. Virol. 2005;79:12117.

30.Wagner AD, Goronzy JJ, Matteson EL, Weyand CM. Systemic monocyte and T-cell activation in a patient with human parvovirus B19 infection, Mayo Clin. Proc. 1995;70:261.

31.Park SJ, Kim JH, Ha TS, Shin JI. Association of parvovirus B19 infection with systemic lupus erythematosus: role of Th1 predominance, J. Rheumatol. 2011;38:1221.

32.Kerr JR, Barah F, Mattey DL, Laing I, Hopkins SJ, Hutchinson IV et al. Circulating tumour necrosis factor-alpha and interferon-gamma are detectable during acute and convalescent parvovirus B19 infection and are associated with prolonged and chronic fatigue, J. Gen. Virol. 2001;82:3011-3019.

33.Lauweyrs BR, Garot N, Renauld JC, Houssiau FA. Interleukin-10 blockade corrects impaired in vitro cellular immune response of systemic lupus erythematosus patients, Arthritis Rheum. 2000;43:1976-1981.

34.Lauweyrs BR, Houssiau FA. Involvement of cytokines in the pathogenesis of systemic lupus erythematosus, in Cytokines and Chemokines in Autoimmune Disease. P. Santamaria and P. Hackett, Eurekah.com and Kluwer Academic/Plenum, 2003. 


\section{European Journal}

of case Reports in

Internal Medicine

35.Toan NL, Sy BT, Song le H, Luong HV, Binh NT, Binh VQ et al. Co-infection of human parvovirus B19 with Plasmodium falciparum contributes to malaria disease severity in Gabonese patients, BMC Infect. Dis. 2013;13:375.

36.Scroggie DA, Carpenter MT, Cooper RI, Higgs JB. Parvovirus arthropathy outbreak in south-western United States, J. Rheumatol. 2000;27:2444.

37. Naides SJ. Rheumatic manifestations of parvovirus B19 infection, Rheum. Dis. Clin. North Am. 1998;24:375-401.

38.Pavlovic M, Kats A, Cavallo M, Shoenfeld Y. Clinical and molecular evidence for association of SLE with parvovirus B19, Lupus 2010;19:783-792.

39.Pugliese A, Beltramo T, Torre D, Roccatello D. Parvovirus B19 and immune disorders, Cell Biochem. Funct. 2007;25:639-641.

40. Meyer O. Parvovirus B19 and autoimmune diseases, Joint Bone Spine 2003;70:6-11.

41.Kozireva SV, Zestkova JV, Mikazane HJ, Kadisa AL, Kakurina NA, Lejnieks AA et al. Incidence and clinical significance of parvovirus B19 infection in patients with rheumatoid arthritis, J. Rheumatol. 2008;35:1265-1270.

42.Chen DY, Chen YM, Lan JL, Tzang BS, Lin CC, Hsu TC. Significant association of past parvovirus B19 infection with cytopenia in both adult-onset Still's disease and systemic lupus erythematosus patients, Clin. Chim. Acta 2012;413:855-860.

43.Shauer A, Gotsman I, Keren A, Zwas DR, Hellman Y, Durst R et al. Acute viral myocarditis: current concepts in diagnosis and treatment, Isr Med Assoc J 2013;15:180-185.

44.Terhes G, Jenei M, Bereg E, Túri S, Deák J. Neurologic consequence of a parvovirus B19 infection, J. Clin. Virol. 2013;56:156-158.

45.Wildig J, Michon P, Siba P, Mellombo M, Ura A, Mueller I et al. Parvovirus B19 infection contributes to severe anemia in young children in Papua New Guinea, J. Infect. Dis. 2006;194:146.

46.Segovia JC, Guenechea G, Gallego JM, Almendral JM, Bueren JA. Parvovirus infection suppresses long-term repopulating hematopoietic stem cells, J. Virol. 2003;77:8495-8503.

47.Lieberman LA, Tsokos GC. The IL-2 defect is systemic lupus erythematosus disease has an expansive effect on host immunity, J Biomed. Biotechnol. 2010;2010:ID740619. 